\title{
Research of Talents Training Mechanism Reform in Local Universities Qingfeng Sun ${ }^{1, a}$, Jianguang Zhao, b and Cuijuan Zhu ${ }^{3, c}$ \\ ${ }^{1,2,3}$ Automobile and Civil School of Beihua University, Jilin China, 132013 \\ abhdxsqf@163.com, ${ }^{b} 573567935 @ q q . c o m,{ }^{c} z c j 19818 @ 163 . c o m$
}

Keywords: Local universities; Talents training; Mechanism reform; Research

\begin{abstract}
The local Universities are important bases for training applied and practical talents. According to the supply and demand for talents in the current market, the major issue of local universities in China is to perfect the local university talents training mechanism, improve the quality of talents training and break down the last kilometer talents transport system. Based on the analysis of talents training mechanism in domestic and foreign universities, the author brings out reforming ideas and operational safeguards of talents training mechanism in universities.
\end{abstract}

\section{Introduction}

Currently, the contradiction is prominent between the structure of university talents training and the labor market. For example, education has emphasis on theory-based culture of academic talents no matter for undergraduate or graduate, which means the lack of training applied talents. The significant deviations between the talents specifications and labor market needs are obvious. For instance, the labor markets have stronger demand of practical, versatile and innovative talents while the bachelors, masters and doctors in local university are often difficult to meet the needs of employers. This makes a lot of difficulties for graduates' employment while the businesses face the difficulties to recruit the right people.

The contradiction between supply and demand for talents has become increasingly prominent, which is caused by the shortage of innovative, practical, versatile talents. This fully exposes that the existing talents training system has been unable to meet the needs of the community. In this paper, the author proposed talents training mechanism based on multi-agent supply side by giving up the long time cultivating mechanism of a single subject under the support of policy orientation to explore solutions to these problems.

\section{Research Status}

Foreign Research Status. The foreign researches on cultivation mechanism for universities carried out earlier with characteristics. Germany emphasized on practical experience and capacity for action-oriented research study, which focused on converting the theory and practice into study situations and work situations in order to improve students' professional competence and comprehensive ability and enhance students' ability for sustainable development. British researchers focused on intercourse skills, the ability to use the number, Engineering Technology and problem-solving skills which emphasized culture of comprehensive vocational ability breaking the academic system of traditional knowledge standard of professional competence center and emphasizing work experience in order to make education and training meet the requirements of industry fully adapting to modern society Lifelong Learning and Career Education trend. American studies emphasize practicality and universality which combined the occupational and academic binding focusing on the integrated capability, emphasizing students' career education for social side and concerning about the development of individuality which reflected the knowledge economy and society on the overall quality of people's requirements. Australia focused on the integrated capability research with particular emphasis on migration and the ability to apply knowledge and skills in novel contexts for lifelong learning research.

In summary, the foreign research valued the Integrated Learning Ability of business-oriented, comprehensive capabilities of Professional and research of career education, which is worth 
learning. The limitations reflect a lack of systematic research on training mechanism for universities and their own rules and characteristics, which are the research to practical needs with fragment pieces.

Domestic Research Status. Fig. 1 shows that the domestic research on personnel training mechanism in local universities grow with each passing day. Domestic scholars' researches about the social adaptation of universities mechanism are under the popularity realization of higher education and adapt to the dynamic changes in the socio-professional technical deployment [1]. Existing studies have focused on three issues: first, research on preliminary discussions and define of the goal, functions and types in talents training [2,3]; second, study on the type of talents, professional structure and course structure, in order to make some theoretical groundwork on adapting market demand as well as talents training in the practice specialties [4]; third, according to the trend of technical upgrading, changes in industrial structure and socio-professional positions rheological dynamic development, the researches should be made for students to adapt to future research professional competence positions performed [5].

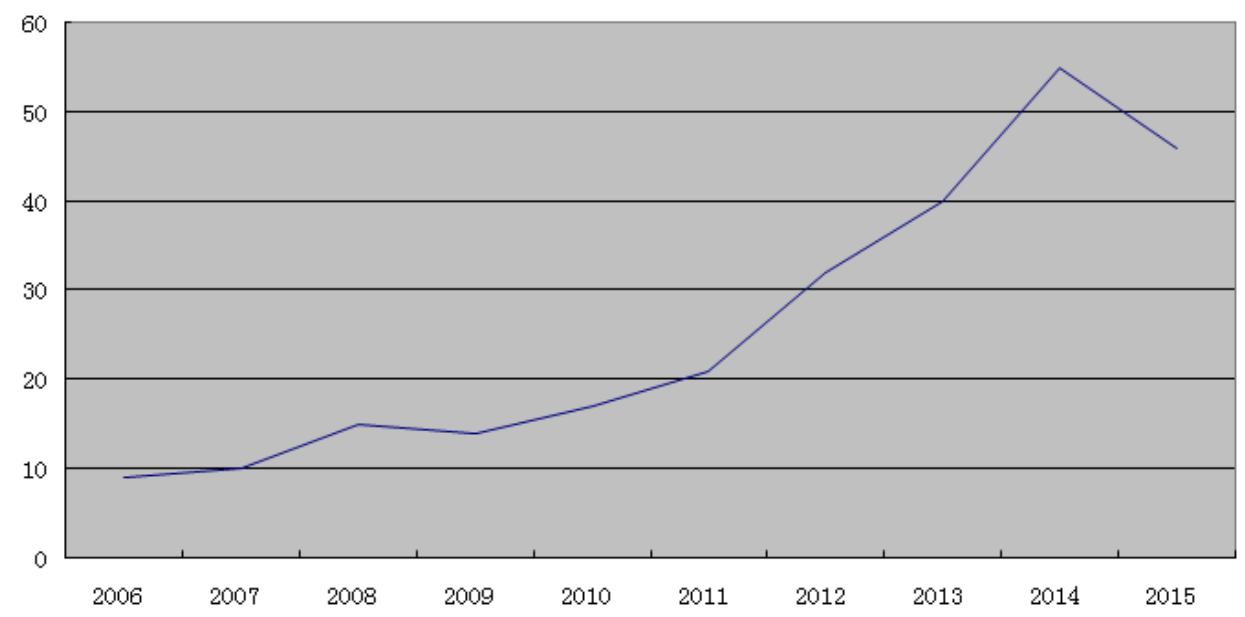

Figure 1. Literature output on Research of Personnel Training Mechanism in Local Universities

In summary, the limitations of domestic research reflected in the following aspects: first, the lack of targeted operational research makes the actual talents training in universities face the requirements of the profession by no clear theoretical support; the second, talents cultivating with experience of specialist or undergraduate training are often in a serious condition of theory divorced from reality; third, we are in the lack of a systematic study of university talents training mechanism. For practical needs, many scholars tend to a foreign models or theoretical applied research.

\section{Talents Training Mechanism Reform}

Update the Concept of Talents Training. The key of deepening education reform is to update the concepts of education with the core of the reform on talents training system in order to improve the level of training talents. It is important to establish a comprehensive concept of development and strive to create high-quality all-round development of talents. Establish the concept for all students that everyone could be talent in order to promote student growth and success. Establish the concept of diversity talents which means respect the personal choice and encourage the development of personality in eclectic talents training. Establish the concept of lifelong learning in order to lay the foundation for sustainable development [6]. Strengthen cooperation among schools, schools and enterprises, schools and research institutions as well as Sino-foreign cooperative joint training for other ways to form an open, flexible talents training system with interoperable channels and a wide choice.

Innovative Training Model. It is important to adapt to the needs of national and social 
development, follow the rules of education and talents growth, deepen educational reform, innovation teaching methods and explore a variety of training methods to make the formation of situation by emerging various kinds of talents and innovative talents.

Reform of Education Evaluation System. Improve education teaching evaluation. According to the concept of talents and training objectives, establish scientific and diverse evaluation criteria. Implement more educational quality evaluation activities by the government, schools, parents and all aspects of social participation [7]. Record the student growth and improve the overall quality of the evaluation. Explore a variety of evaluation methods for the development of students in and encourage students to be optimism, self-reliance and talents.

Improvement of Talents Evaluation and Selection System. To create a good environment for the scientific talents training, establishing scientific and social evaluation discovery mechanism based on job responsibilities, character, ability and performance-oriented scientific. Strengthen the test in practical ability in talents selection and overcome the tendency of purely pursuing social employment qualifications [8].

\section{Guarantees in Operating Talents Training Mechanism}

Perfect Education Management System. Focusing on transform government functions and decentralization, we should deepen the education management system, improve public education services, clear responsibility of local government, regulate the behavior of the school, and promote management rules in order to make the formation of an order education management system with public affairs separation, clear responsibilities and coordination. Local government is responsible for the implementation of policies, educational reform experiment, responsibility of education reform development and stability according to the division of responsibilities within the area.

Strengthen Education Manpower of Local Government. Improve co-ordination of regional higher education of provincial local government for further increase. Perfect higher education institutions of the primary management by provincial government, set and adjust reasonable discipline for universities in order to improve the management level and teaching quality [9]. Examine the qualifications of Higher Education and approve the establishment of the implementation of specialist, Bachelor of Management approval Universities provincial government determined to grant degree awarding units and units for the master's degree.

Transformation of Educational Management Functions. Local government should perform their overall planning, policy guidance, supervision and management responsibilities earnestly to provide public education services in order to establish and improve the public education service system, achieve the equalization of basic public education services gradually and keep the maintenance of fair and orderly education. Changing a single direct management of the school, government should take advantages of the comprehensive application of the legislation, funding, planning, information services, policy guidance and necessary administrative measures to reduce unnecessary administrative intervention as well as improve the effectiveness of government decision-making and scientific management. Education Advisory Committee should be established to provide advice Demonstration of educational reform and development, improve the scientific major educational decisions [10]. Establish and improve the basic national education standards. Government should make integration of national education quality monitoring and evaluation mechanism and resources to improve the monitoring and evaluation system, monitoring and evaluation reports regularly published. Strengthen supervision and inspection of education and improve education accountability mechanisms. Foster professional education services. Perfect the self-regulation system of intermediary organizations to improve education access, financing, regulatory and industry. Industry associations, professional societies, foundations and other social organizations should play an active role in local university governance.

Improve Teacher Management System. Improve and strictly implement teacher access system for strict doorway of teachers. Government set the qualification standards for improving the working standards and conduct requirements. Established a regular registration system of teachers' 
certification. Provincial education administrative departments organize unified university teachers job recruit, job classification, training, other management training and assessment functions.

Improve the Funding Mechanism. Further clarify the responsibilities of local governments to provide services of higher education and improve education funding mechanism to ensure a stable source of funding and growth of the school. Local government develop and gradually improve college students per capita funding for basic standards and regional financial allocations per student basic standards in accordance with national conditions and the basic standards of education and teaching basic needs [11].

Promote Management in Universities by Law. Local government should fulfill duties according to law education in accordance with the rule of law requires, explore the reform on administrative law enforcement system and educational mechanism to implement the responsibility system for administrative law enforcement education in order to deal with violations of laws and regulations against the interests of the educated, disrupt order and other education activities and maintaining schools, students, teachers, principals and organizers of the rights and interests. Improve the education system of public information to protect public information, participation and supervision of education. Local universities should establish and improve compliance with the law, reflecting its own characteristics and charter school system, law schools, and strict school and fulfill teaching and management responsibilities. Respect for the rights of teachers, strengthen teacher management and safeguard students' right to education by meeting the fair and just principles of the implementation on reward and punishment. Improve education relief system in line with the rule of law.

\section{Acknowledgements}

Project financial support for the Office of Educational Sciences in Jilin Province: "A Research of local universities talents training mechanism reform and policy " (GH11077)

\section{References}

[1] Lian Yi. Discussion General Universities and Training Mechanism of Market Competitiveness [J] based Tsinghua University Education Research, 2014, 06:45-48

[2] Z.G Chen. Innovative Training Mechanism [J]. Works University, 2014, 01 :23-24

[3] L.G Qin. Exploration and Reflection Creative Talent Training Mechanism [J] Chinese university teaching, 2014, 10: 4-8.

[4] Q. Guo. Study on Innovative Teaching System of Higher Learning Under the Perspective of Social Quality Theory [J] Industry and Information Technology Education, 2013, 04: 5-9.

[5] C.L Huang. Based Innovative Teaching Management System Innovative Talents Training [D]. Hunan University, 2005.

[6] Y.D Li. Research Innovations of University Teaching Management System under the Concept of Creative Talents [J] Chinese school education, 2014, S3:.. 221.

[7] W. Yang. Talents in Local Universities Mechanism Innovation Perspective On combination [J] Educational Theory and Practice, 2015, 21: 8-9.

[8] X.H Zhu, S.C Huang. Talents Innovation Universities mechanism [J] Front Theory, 2006, 24 : 40-41.

[9] H.W Zhu. Reform of teaching management system of universities and universities, cultivating innovative talents [J] Weekly Market Theory, 2006, 08: 26-27.

[10]L.M Xin, Y. Zhou, N. Zhang. Electric Information Research Talents Training Mode of College Enrollment System [J] Education Forum, 2011, 20: 129-130. 
[11]Q. Li. Innovative talents and Innovations of University Teaching Management System [J]. Exam Week, 2011, 19: 195-196. 